\title{
BEHOEFTE AAN EEN NIEUWE CONCEPTIE?
}

\section{door Prof. A. Goudeket}

Onder de titel „,de consequentie van een ontwikkeling” heeft de heer Pon in het nummer van januari 1961 van dit maandblad een artikel geschreven waarin hij, zoals hij zelve zegt, een poging doet te onderzoeken:

- of de ontwikkelingen die de conceptie der inrichtingsleer zo sterk wijzigden en verhelderden, niet mede de conceptie van de accountantsfunctie en dus van de controleleer moeten doen evolueren

- of andere invloeden eventueel op deze conceptie werkzaam zijn

- hoe een in de besproken ontwikkelingen passende conceptie zou kunnen worden geformuleerd.

Hij eindigt zijn artikel met de volgende woorden:

„Wij menen dat de in het voorgaande ontwikkelde summiere poging om een dergelijke conceptie te geven, rekening houdt met de ontwikkeling der verantwoordingswetenschappen en met die der maatschappelijke omstandigheden. De waarde van alle vroegere concepties, gevormd onder andere stand van wetenschap en omstandigheden, wordt volledig erkend en kritiek daarop is verre van ons. Wij hopen slechts, dat bekwameren dan wij de nieuwe conceptie beter zullen funderen dan wij het thans hebben kunnen doen, opdat het accountantsberoep in Nederland de vrijheid vinde zich aan te passen aan en te ontplooien in nieuwe omstandigheden."

Uit het gehele betoog en in concreto uit het geciteerde slot blijkt dat Pon van oordeel is dàt er behoefte bestaat aan een gewijzigde conceptie en dat hij meent die nieuwe conceptie te hebben gevonden, waarbij hij de hoop uitspreekt dat bekwameren dan hij de nieuwe conceptie beter zullen funderen dan hij heeft kunnen doen.

Ik ben de heer Pon dankbaar voor hetgeen hij het beroep in zijn artikel heeft gegeven omdat zijn betoog tot nadenken en bewustwording stemt ten aanzien van hetgeen was, is en worden zal met betrekking tot de grondslagen van het accountantsberoep.

Als uitgangspunt voor mijn betoog heb ik niet zulk een aardig sprookje bij de hand als Pon, maar ik werd wel herinnerd aan de zeer realistische spreuk die bij een van mijn Amerikaanse vrienden aan de wand hangt: "If two men have the same opinion, one is superfluous." Welnu, ik constateer dat geen van ons beiden overbodig is want ik ben het met de schrijver niet eens. Wegens de betekenis van het onderwerp voel ik de behoefte in dit maandblad de overwegingen uiteen te zetten op grond waarvan mijn mening afwijkt van die van de schrijver.

Mijn bezwaren tegen het artikel van Pon zijn van principiële en van incidentele aard:

I. principieel: ik ben van mening dat er geen behoefte is aan een nieuwe conceptie van de accountantsfunctie en dus van de controleleer.

II. incidenteel: met diverse beweringen en overwegingen in het artikel ben ik het bepaald oneens. 


\section{Er is geen behoefte aan een nieuwe conceptie van de accountantsfunctie en dus van de controleleer.}

Wanneer men het artikel van Pon goed leest dan blijkt het uitgangspunt voor zijn probleemstelling te zijn de voor-onderstelling dat de accountants weliswaar enerzijds het principe waarop hun controleleer is gebouwd en anderzijds de hun ten dienste staande controlemiddelen en -technieken kennen, maar dat zij niet zeker zijn van de verbinding tussen die beide; anders gezegd: het blijft een vraag waarop en in welke omvang de middelen en technieken in concreto moeten worden toegepast. Van de creatie van de leer van het gewekte vertrouwen tot op de huidige dag heeft elke accountant zich afgevraagd of de omvang waarin hij zijn technieken toepaste niet groter of kleiner was dan het principe vereiste (bladzijde 10). Op bladzijde 11 stelt schrijver zich dan de vraag of de ontwikkelingen die de conceptie der inrichtingsleer wijzigden niet mede de conceptie van de accountantsfunctie en dus van de controleleer moeten doen evolueren. Via een reeks argumenten en beschouwingen komt Pon, zoals reeds opgemerkt, tenslotte dan tot de conclusie dat er inderdaad behoefte is aan een nieuwe conceptie en geeft aan welke die naar zijn inzicht zou moeten zijn.

Ik vraag mij in gemoede af op welke gronden de schrijver het aangegeven uitgangspunt voor zijn betoog heeft menen te mogen of moeten kiezen. Is het werkelijk redelijk te stellen dat de huidige beroepsgenoot, voorzover hij zich tot de serieuze beroepsbeoefenaren rekent, niet zeker is van de verbinding tussen het principe waarop de controleleer is gebouwd en de controlemiddelen en -technieken die hij in de praktijk toepast?

\section{De evolutie van de controleleer is niet bij die van de inrichtingsleer achtergebleven.}

Is het reëel dat Pon zich afvraagt of de ontwikkelingen in de conceptie van de inrichtingsleer niet mede de conceptie van de controleleer moeten doen evolueren? Is dit geen gevaarlijke retoriek, in die zin dat bij de lezer een verkeerde indruk wordt gewekt omdat een uitspraak wordt gedaan waaruit slechts kan worden afgeleid, dat de controleleer niet evolueerde? Als men verder leest wordt men versterkt in de indruk dat Pon ook heeft bedoeld dit uitdrukkelijk te stellen (zie onder andere bladzijde 12). In het slotwoord, waarin de waarde wordt erkend van alle vroegere concepties zie ik geen neutralisatie van die indruk, veelmeer een tegenspraak met de inhoud van het artikel.

In een uitstekend artikel hebben Spits en Zandstra ${ }^{1}$ ) in 1959 het nieuwe studieprogramma van het Nederlands Instituut van Accountants voor het vak inrichtingsleer besproken. $\mathrm{Zij}$ schrijven daarin onder andere: „Blijkbaar heeft zich in dit vak sinds het vorige studieprogramma van kracht werd (1940) een ontwikkeling voorgedaan die het Bureau der Examens van het N.I.v.A. aanleiding heeft gegeven om tot een herziening over te gaan." $\mathrm{Zij}$ leggen er terecht de nadruk op dat ieder studieprogramma tegelijkertijd streefprogramma is. Het is toe te juichen dat men de ontwikkeling ook in de naam heeft doen doorwerken: ,van inrichtingsleer naar administratieve organisatie”. Kijk, en nu zijn volgens Pon diezelfde accountants, die een zo prospectieve activiteit en visie aan de dag hebben gelegd op het gebied van de administratieve organisatie, op het terrein van de accountantscontrole stil blijven staan. Is de verwarring in de

1) Van inrichtingsleer naar administratieve organisatie, M.A.B. juni 1959. 
gedachtengang van de schrijver niet ontstaan doordat het nieuwe studieprogramma voor administratieve organisatie tot stand is gekomen, dat wil zeggen de stand van de ontwikkeling thans voor een ieder zichtbaar is gemaakt? Het nieuwe studieprogramma voor de controleleer moet nog komen. Ik hoop dat daarbij ook een gewijzigde benaming van het vak zal worden geïntroduceerd, namelijk „de leer van de accountantscontrole”. De leerstof (die nooit iets anders bedoelde te zijn) zou daarmee juister worden aangeduid. Schrijver noemt die naam eveneens, zij het in een verband waarop ik hierna nog terug kom. Maar dat wil niet zeggen dat de ontwikkeling zelve er niet is; ik beweer dat de controleleer analoog met de leer van de administratieve organisatie is geëvolueerd.

Ik ben mij bewust dat ik het bewijs voor deze uitspraak heb te leveren.

Als uitgangspunt voor mijn bewijsvoering zou ik willen kiezen de interessante beschrijving van de ontwikkeling van de administratie, die Starreveld ${ }^{2}$ ) heeft gegeven. Starreveld spreekt van 12 ontwikkelingsfasen waarvan ik hier de grote lijn moge herhalen:

(1) registratie van geldmiddelen, vorderingen en schulden, met uiterst eenvoudige systematiek casu quo zonder systematische samenhang. Incidenteel voorkomende voorraadregistraties staan normaliter los van de overige administratie;

(2) systematische samenhang tussen de mutaties in de kapitaal- en vermogensbestanddelen waardoor het periode-resultaat kan worden berekend en de balans kan worden opgesteld;

(3) uitbreiding van de registratie ten behoeve van de kwantitatieve voorraadbeheersing en uitgroei tot organisch gestructureerde produktiekostenadministratie;

(4) uitbreiding tot budgetadministratie met gebruikmaking van standaardhoeveelheden en standaardprijzen;

(5) uitbreiding van het administratieplan tot een stelsel van interne en externe communicatie door middel van informatiedragers;

(6) uitbreiding van de administratieve bemoeienis door de komst van electronische administratiemachines:

(a) introductie van vaste regels ten aanzien van routinebeslissingen met betrekking tot de bedrijfsvoering;

(b) toepassing van beoordelingsnormen ter toetsing van rekeningcijfers en van rapportering volgens de uitzonderingsregel;

(c) rechtstreekse communicatie met operationele functionarissen en produktiemachines.

Ik dien thans dus aannemelijk te maken dat de controleleer een ontwikkeling heeft doorgemaakt die vergelijkbaar is met die van de administratieve organisatie, zoals deze in het vorenstaande, aan Starreveld ontleende schema is geschetst. Daartoe is het mijns inziens niet voldoende casuïstisch op te sommen van welke technieken de accountant zich bedient en vast te stellen hoe het doel van de controle op dit moment en detail kan worden omschreven. Allereerst zal moeten worden nagegaan welke de grondslag is die de basis van de evolutie vormde. Hiervoor vinden wij een bepalend uitgangspunt in de leer van het

2) Ontwikkeling van het administratiebegrip, Prof. R. W. Starreveld. M.A.B. mei 1961 als onderdeel van een artikelenrecks over administratie.

m a b blz. 93 
gewekte vertrouwen van Limperg. De accountant als vertrouwensman van het maatschappelijk verkeer ontleent zijn functie aan de behoefte aan het deskundig en onafhankelijk oordeel. De behoefte van het verkeer en het vermogen van de controletechniek zijn de faktoren die het vertrouwen, in de zin van de verwachting, bepalen. De normen voor de beroepsuitoefening vinden derhalve hun grondslag zowel in de rationele eisen van het verkeer als in de controletechniek. Er is niet van een vaste inhoud van de verwachting sprake want zowel de behoefte als de techniek zijn aan wijziging onderhevig. De zekerheid waaraan behoefte bestaat kan nooit een absolute zijn. De grenzen liggen bij het menselijk kunnen, het economisch motief en de stand van de techniek. Nooit echter kan er sprake zijn van een subjectief oordeel. Aldus leert Limperg ons.

Ik concludeer dat in deze waarlijk meesterlijke gedachtengang de basis is gelegd voor de evolutie, niet in de zin dat ontwikkeling toelaatbaar zou zijn maar in de zin dat ontwikkeling een wezenlijke noodzaak vormt. De accountant zal naar het woord van Limperg dus moeten zorgen dat hij de evolutie in de behoefte van het verkeer volgt en wie zal daartoe beter in staat zijn dan deze deskundige, die zelfs een wezenlijke invloed op de verwachting kan en zal uitoefenen? Daarnaast zal hij dan de ontwikkeling in de controletechniek op de voet hebben te volgen, een ontwikkeling die overigens vanzelfsprekend in overwegende mate door de accountant zelve wordt bepaald. Aldus is de evolutie van de inhoud van de functie en daardoor die van de taak van de accountant fundamenteel in de grondslagen verankerd.

Ten aanzien van de evolutie nu dringen zich enige markante kritische momenten op. De historici verhalen dat reeds in de grijze oudheid van de accountant sprake was. Schrijver zal het mij zeker niet ten $\mathrm{k} w a d e$ duiden indien ik mij tot de twintigste eeuw beperk, min of meer dus begin bij de oprichting van het Instituut. Zoals de geschiedenis leert was de accountant in zijn prille verschijningsvorm een boekhoudkundige die zich in zijn arbeid overwegend beperkte tot boekhoudkundige werkzaamheden met hier en daar fragmentarische controlewerkzaamheden. In het begin van deze eeuw ontstond hier te lande echter een beweging die bepalend zou blijken te zijn voor de grote ontwikkeling die het accountantsberoep in Nederland tot de dertiger jaren zou doormaken. In een strijd om te komen tot een zodanige systematisering van de controle dat de verantwoordelijkheid tegenover het publiek en de opdrachtgevers realiter zou kunnen worden gedragen, scheidden enige leden zich af van het N.I.v.A. (achteraf bleek dat het een tijdelijke afscheiding was). Als direct gevolg daarvan ging een controleleer (lees: leer van de accountantscontrole) ontstaan, en deed een tiental jaren later ook de bedrijfseconomie haar intrede. Deze episode valt samen met het moment waarop Volmer laatstgenoemde wetenschap aan de Technische Hogeschool te Delft begon te doceren ${ }^{3}$ ).

In 1926 - zo zou men kunnen zeggen - werd de ontwikkeling die het beroep had doorgemaakt geconsolideerd in de leer van het gewekte vertrouwen, zoals die door Limperg werd geformuleerd tijdens het eerste internationale accountantscongres in Amsterdam: systematische controle, taak gericht op formele „,juistheid" en materiële ,juistheid", een en ander ontleend aan de verwachting van het maatschappelijk verkeer, met - zoals eerder aangeduid - de evolutie als

3) Deze historische schets is overwegend ontleend aan „40 jaren accountancy” door Dr. A. Sternheim. 
wezenlijk element. Moge deze episode in de ontwikkeling de meest spectaculaire zijn, de periode die daarop volgde is er niet minder belangrijk om. Men zou die periode kunnen omschrijven als het tijdperk van de bedrijfseconomie en de administratieve organisatie, ter aanduiding van de elementen die van invloed zijn geweest op de ontwikkeling van de controleleer: de budgetering met haar normatieve verbanden geconcretiseerd in standaardhoeveelheden en standaardprijzen, de steeds voortschrijdende verbetering van de administratieve organisatie waardoor de organische samenhang van de bedrijfshandelingen steeds beter tot zijn recht $\mathrm{kwam}$ en de interne controle doelmatiger werd verzorgd, de reïntegratie van de steekproef, de ,dynamische" controle als pendant van de "dynamische" administratie. Ik moge met betrekking tor de dynamische controle bijvoorbeeld verwijzen naar de uitnemende inleiding van Groeneveld tijdens de Accountantsdag 1953 en naar de vraag die ik de inleider bij die gelegenheid stelde: „Is het eigenlijk niet zó dat het zwaartepunt van de dynamisering niet ligt bij de vaktechniek doch bij de verklaring, namelijk dat er sprake is van een dynamische verklaring, namelijk niet een verklaring bij die jaarrekening maar van die onderneming, met de door de accountant gecontroleerde organisatie, de gecontroleerde bedrijfshandelingen en de beoordeelde grondslagen van resultatenberekening en waardering?"

Ter completering van het beeld van de evolutie mag tenslotte niet onvermeld blijven dat ook de introductie van machines en machinesystemen een stempel heeft gedrukt op de taak van de accountant en ik meen bijvoorbeeld met betrekking tot de invloed van de automatie te mogen stellen dat de "research en ontwikkeling" op het gebied van de accountantscontrole nauwelijks achter staat bij die op het terrein van de administratieve organisatie.

Geeft de verantwoording van de directie een aanvaardbare voorstelling van zaken (Pon's $3 e$ object)?

Moge naar mijn mening uit het vorenstaande een fascinerende ontwikkeling van de controleleer blijken, ik ben daarmede nog slechts gedeeltelijk doorgedrongen in hetgeen schrijver en mij scheidt, namelijk dat volgens Pon wèl en volgens mij geen behoefte bestaat aan een gewijzigde conceptie van de accountantsfunctie, met name niet voor de bijzondere functie die wij plegen te noemen de algemene controle en welke is gericht op een oordeel omtrent de jaarrekening, het verantwoordingsstuk van de leiding van de huishouding. Het ging en het gaat bij die algemene controle om de vaststelling, dat die verantwoording een aanvaardbare voorstelling geeft van het resultaat over de verslagperiode en van de kapitaal- en vermogensposirie per het einde van de periode (derde object van Pon, bladzijde 15). Ten overvloede stel ik vast dat te dien aanzien geen verschil bestaat tussen "huidige" en "nieuwe" conceptie. Ik ga op de specifieke eisen waaraan die verantwoording daartoe moet voldoen hier niet in en beperk mij tot de enkele opmerking, dat hier nog een belangrijke taak voor het accountantsberoep ligt. Het gamma van interpretaties dat met betrekking tot het door ons gehanteerde begrip "goed koopmansgebruik" mogelijk is en de brede tolerantie die ten aanzien van de uitkomst mogelijk blijkt, houden voor het maatschappelijk verkeer een element van onzekerheid in. De inhoud van de verklaring, die het middel is waarmee het oordeel van de accountant in het verkeer wordt gebracht, is in de loop der jaren geëvolueerd. De jaarrekening 
heeft meer en meer een dynamische betekenis gekregen en steeds meer heeft de verklaring dus betrekking op een betrekkelijk willekeurige dwarsdoorsnee in het leven van de huishouding, of zoals Groeneveld in zijn eerder aangehaalde inleiding zei: ,het gaat om één stip op de lijn der voortschrijdende jaartotalen van 12-maandsresultaten." De accountant houdt bij zijn oordeel ook rekening met de prospectieve functie van de jaarrekening, dat wil zeggen met de functie die de jaarrekening voor de lezer vervult bij diens extrapolatie, bij de projectie van diens toekomstverwachting dus.

Nu dacht ik dat dit alles het resultaat is van de evolutie-noodzaak die Limperg in zijn conceptie van de leer van het gewekte vertrouwen heeft ingebouwd. Het verschil van mening dat tussen Pon en mij op dit punt bestaat zou in wezen wel eens kunnen blijken enkel een misverstand te zijn, in die zin dat het Pon in feite niet gaat om een gewijzigde conceptie doch om een meer naar buiten brengen ${ }^{4}$ ) van de concrete betekenis van de goedkeurende verklaring zoals dat ook in Amerika langs verschillende wegen plaats vindt (vaste formule voor de verklaring en publicaties in de geest van "What does an auditor's certificate mean?"). Op dit gebied vindt de heer Pon mij geheel aan zijn zijde; reeds een tiental jaren geleden heb ik daarvan in een inleiding voor een accountantsdag blijk gegeven. Maar dat is geheel iets anders dan een gewijzigde conceptie.

\section{De andere door Pon genoemde objecten.}

Indien ik de beide of zelfs de drie andere objecten van Pon beschouw, dan beweer $i k$ dat deze al zeer lang zonder meer elementen van het controleprogramma zijn. In mijn eigen woorden weergegeven luiden deze:

- eerste object: beoordeling van de conceptie van de interne organisatie en de daarin verweven middelen en maatregelen van interne controle en vaststelling dat de uitvoering bevredigend heeft plaats gevonden;

- tweede object: constateren dat de verantwoording van de directie op de administratieve verantwoording aansluit, in de zin dat zij het gehele bedrijfsgebeuren, zonder dat daaruit iets essentieels wordt weggelaten omvat;

- vierde object: beoordelen van de doelmatigheid van de administratieve organisatie.

Ik heb minder aarzeling dan Pon om zijn vierde object in één adem met de andere objecten te noemen. Ik ben van mening, dat daar waar de beroepsuitoefening op het goede niveau plaats vindt, dat object reeds lang een wezenlijk element vormt van de accountantsfunctie. Doordat het arsenaal van hulpmiddelen waaruit kan worden gekozen groter wordt en die hulpmiddelen intensiever ingrijpen in de interne organisatie wordt dit vraagstuk gradueel van grotere betekenis. Dit heeft er toe geleid dat er de laatste jaren in beroepskringen zelfs over wordt gesproken het oordeel van de accountant ten aanzien van de interne organisatie aan de inhoud van de verklaring toe te voegen.

4) Een lofwaardige start inzake publicaties over het accountantsberoep is te zien in de artikelen in het tijdschrift van de Maatschappij voor Nijverheid en Handel en in het Financiële Dagblad. 
Er bestaat geen wezenlijk onderscheid tussen een controleplan volgens de buidige conceptie en volgens Pon's conceptie.

Wanneer Pon en ik bij een zelfde huishouding in het kader van een algemene controle het controleplan zouden opstellen, hij volgens de gewijzigde en ik volgens de huidige conceptie, dan twijfel ik er nauwelijks aan, of wij zouden tot een gelijke taak komen. $H i j$ gaat ervan uit dat de administratie zelfcontrolerend moet zijn en dat ook is, waarbij de accountant de behoefte dekt aan controle op de laatste schakel in de keten van zelfcontrolerende verantwoordingen. Blijkens zijn eerder genoemde objecten van controle zal zijn controleplan dan bestaan uit controlehandelingen gericht op die laatste schakel en toetsing of de zelfcontrolerendheid van de voorgaande schakels inderdaad aanwezig is. Zowel tegen het uitgangspunt als tegen het doel meen ik ernstig bezwaar te moeten maken. Voor mijn bezwaar tegen het uitgangspunt kan ik niet beter doen dan te verwijzen naar hetgeen Pon zelve als controle-object vermeldt, namelijk dat hij zal moeten vaststellen dat de zelfcontrolerendheid van de voorgaande schakels aanwezig is. Niet vóór doch eerst nà die vaststelling zal blijken of van zelfcontrolerendheid sprake is. In de redenering van Pon wordt de functionele noodzaak van ,controle" miskend. Door het aanduiden van de noodzaak van vaststelling van de zelfcontrolerendheid is die miskenning geëlimineerd. Ik moge in dit verband ook verwijzen naar een uiteenzetting van Van Rietschoten in het M.A.B. van juni $1954^{5}$ ). Voor wat het doel betreft richt mijn bezwaar zich op het feit dat in de door Pon voorgestelde conceptie de functie van de accountant erop is gericht vast te stellen of de topleiding (diezelfde topleiding die een bepalende invloed heeft op de bedrijfshandelingen, op de organisatie en op het zelfcontrolerend zijn van die organisatie) wel een verslag uitbrengt dat aansluit aan de verantwoording die intern aan haar wordt afgelegd. Is dat niet een onwezenlijk uitgangspunt? Wordt daarmede niet een, door Pon zeker niet gewilde, suggestie gedaan in de richting van boos opzet bij die topleiding? In het andere geval toch zal niet behoeven te worden getwijfeld dat ook ten aanzien van de laatste schakel dezelfde graad van zelfcontrole zal kunnen worden geconcipieerd.

$I k$ ga ervan uit, dat de accountant het eigen oordeel moet baseren op eigen arbeid. Ter vermijding van misverstand zij opgemerkt dat ik met ,eigen arbeid" niet het ingeburgerde begrip ,eigen actie" bedoel. Toetsen en gebruik maken van de interne controle is immers wel ,eigen arbeid" doch niet „eigen actie” en ik zou in plaats van "eigen actie" dan ook liever het begrip „zelfstandige controlehandelingen" hanteren. Om nu bij de conceptie van die eigen arbeid voor iedere bijzondere functie tot de meest rationele uitvoering te komen moet bij de werkzaamheden een optimum worden nagestreefd. Afgezien van het feit dat Limperg's leer te dien aanzien geen twijfel laat, moge ik hier nog verwijzen naar A. $\mathrm{Mey}^{6}$ ) die in een uiteenzetting naar aanleiding van de artikelen van Tempelaar, Diephuis c.s. in zijn inleiding als volgt schrijft (verkort weergegeven):

"In het onafhankelijk en deskundig oordelen ligt een der meest specifieke betekenissen van de functie van de accountant als vertrouwensman van het maatschappelijke verkeer. In de kundigheid, de onafhankelijkheid en de zelf-

5) „De betekenis van de interne controle voor de accountantscontrole” door Prof. A. van Rietschoten in M.A.B. juni 1954.

$\left.{ }^{6}\right)$ „Interne controle en de techniek der accountantscontrole” door Prof. Dr. A. Mey in M.A.B. maart 1956. 
standigheid van zijn oordeel over de weergave van de bestuursdaden in de verslaglegging ontstaat een zekerheid die vanuit het bestuursorgaan zelve nooit ontstaan kan. Bij de arbeid moet een techniek van werken worden gevolgd die de mogelijkheid van een zelfstandig en onafhankelijk oordeel insluit en moet aangepast zijn aan wat dat oordeel moet inhouden. Het werkplan zal geen werk mogen omvatten, dat tot die oordeelvorming niet vereist is. Geen werk mag worden weggelaten dat daartoe nodig is."

Mijn controleplan zal dan bestaan uit een harmonisch geheel van zelfstandige controlehandelingen en het gebruik maken van de interne controle nadat ik deze op haar doelmatige conceptie en de goede werking heb getoetst. Daarbij zal ik controlemethoden hanteren die doelmatig zijn in het kader van hetgeen ik daarmee wil bereiken en dit alles tezamen vormt de „eigen arbeid" gericht op het kunnen uitspreken van een oordeel. En onder die doelmatige controlemethoden heeft naar mijn overtuiging de steekproefmethode in de huidige conceptie van de controleleer een waardige plaats; het onderscheid tussen het waarschijnlijkheids- en zekerheidsoordeel is naar mijn mening ,,weggeëvolueerd". Ik volsta met een verwijzing naar de recente publicaties van Louwers, Drs. $\mathrm{H}$. Mey enzovoort. Ook voor de rechtvaardiging van de steekproefmethode bestaat geen behoefte aan een nieuwe conceptie van de controleleer.

Waar de arbeid die volgens beide concepties moet worden verricht, blijkt gelijk te zijn, wil het mij voorkomen dat deze logischer uit de oude dan uit de nieuwe conceptie kan worden afgeleid.

\section{Pon's conceptie miskent de betekenis van de accountantsfunctie voor de leiding van de onderneming.}

Het valt mij op dat de functie van de accountant volgens Pon geheel extern is gericht. Een functie ten behoeve van de inwendige organisatie, met name ten behoeve van de opperste leiding, schijnt er in de nieuwe conceptie niet meer bij te zijn.

Door het onvermeld laten van de ,vertrouwensfunctie ten behoeve van de leiding" wordt de grote betekenis van de accountantsfunctie voor de leiding miskend. Die betekenis ligt niet alleen in de positieve bijdrage van de accountant bij de externe verslaglegging om deze op een zo hoog mogelijk niveau te brengen en daardoor de plaats van de onderneming op de vermogensmarkt mede te bepalen. De uitkomst van de arbeid van de accountant heeft zeer bepaald ook een interne betekenis voor de leiding. Door zijn deskundig en onafhankelijk oordeel voorziet de accountant in een behoefte aan interne zekerheid van de leiding, namelijk zoals eerder opgemerkt dat de administratie die zelfcontrolerend is geconcipieerd dat ook waarlijk is en dat de gehanteerde grondslagen en normen in hun conceptie doelmatig zijn en op de juiste wijze zijn toegepast. Hoe doelmatig de administratieve organisatie ook moge zijn geconcipieerd, in het kader van haar verantwoordelijkheid heeft de opperste leiding behoefte aan deze zekerheid en deze kan alleen worden verschaft door de accountant. Het gaat hier dus niet - zoals Pon stelt - om een fase op de weg naar het enige doel, doch om een zelfstandig doel, zoals ook Limperg dat reeds aanduidde. Ook aan dit facet van de accountantsfunctie wijdt A. Mey in zijn voren- 
genoemd artikel een interessante beschouwing. Ik voel $\mathrm{mij}$ in deze geschraagd door een belangwekkende beschouwing van Van Rietschoten ${ }^{7}$ ).

\section{Opmerkingen over diverse beweringen en overwegingen.}

$\mathrm{Na}$ de principiële beschouwing zou ik ten aanzien van de specifieke inhoud van het artikel van Pon kort willen zijn.

(1) Allereerst zou ik een misverstand uit de weg willen ruimen, zij het een ander dan Pon ten tonele voert. Op bladzijde 12 stelt hij dat de leer van de administratieve organisatie zich heeft vrijgemaakt van het misverstand dat het toepassen van controletechnieken uitsluitend of althans in hoofdzaak des accountants was.

Er bestond, aldus Pon, een vermenging van interne en externe controle bij de taakvervulling door de externe controleur, die zich bij bedoeld misverstand aanpaste. Het zou schadelijk zijn voor het accountantsberoep - aldus nog steeds Pon - wanneer de gevolgen daarvan thans niet ook volledig uit de controleleer zouden worden verwijderd. Deze opmerking van Pon vloeit voort uit hetgeen hij op bladzijde 11 zegt, namelijk dat vrijwel alle controlemiddelen en -technieken die vroeger uitsluitend tot het terrein van de controleleer schenen te behoren, in de administratieve organisatie kunnen worden aangewend.

Het aan de orde stellen van dat misverstand berust op een misverstand.

Reeds in het boek van Sternheim „Administratieve inrichtingsleer” (uitgegeven in 1927) lees ik in hoofdstuk III onder het punt „controlestelsels in het beheer" een opsomming waaruit bepaaldelijk niet kan worden afgeleid, dat zelfs toen het toepassen van controletechnieken als het uitsluitende domein van de accountant zou worden beschouwd. In 1936 schreef A. Mey over de noodzaak van een normatieve theorie voor de accountantscontrole. Van een vermenging tussen interne en externe controle was daarbij zeker geen sprake. Integendeel: de accountant als „facultatief intern controleur” werd als uitzondering ten tonele gevoerd en wel alleen voor die gevallen waarin de interne organisatie van de huishouding daartoe aanleiding gaf. In mijn intree-rede in 1955 als buitengewoon hoogleraar in Rotterdam legde ik de nadruk op de betekenis die de controleleer heeft voor de administrateur hetgeen evenmin op een monopolie van de accountant ten aanzien van de controletechnieken wijst.

(2) Op bladzijde 12 stelt de schrijver, dat door het hierboven gestelde misverstand de accountants ,de administratie gingen controleren”. Het later in de controleleer vastleggen van het principe dat zij in feite alleen de slotverantwoording moesten controleren was een grote stap. Sternheim's controleleer, die in feite een leer der controlemiddelen en -technieken was, werd op die manier belangrijk aangevuld. Pon acht het zelfs beter te zeggen dat een nieuwe leer, die van de accountantscontrole ontstond. Ik ben het met deze uitspraak niet eens. Wanneer wij het boek van Sternheim „De accountantscontrole (algemene beginselen)" (uitgegeven in 1924) opslaan en hoofdstuk I herlezen dan blijken onomstotelijk twee feiten: ten eerste dat Sternheim

$\left.{ }^{7}\right)$ Arrikel in het Tijdschrift van de Maatschappij voor Nijverheid en Handel „De betekenis van de controlerende functie van de accountant" door Prof. A. van Rietschoten. 
over de accountantscontrole schrijft en dat het door ons gehanteerde begrip „controleleer" toen reeds niets anders bedoelde aan te duiden dan de leer van de accountantscontrole. Zoals ik in de aanhef van dit artikel memoreerde deel ik de mening dat het zin heeft die naam voor het vak controleleer te introduceren. Het gaat daarbij echter niet om een principiële doch slechts om een praktische overweging in dezelfde geest waarin wij er ook naar streven het vroeger in accountantsverklaringen gehanteerde woord ,juist" te veranderen in ,getrouw" of ,aanvaardbaar." Ten tweede blijkt Sternheim uitdrukkelijk te stellen dat het er bij de accountantscontrole om gaat een verklaring te geven bij een verantwoordingsstuk, een volkomen analogie dus met hetgeen Pon stelt. Het doel van de accountantscontrole was en is de controle van de - in de terminologie van Pon - slotverantwoording. Ik ben van mening dat het in het kader van de functie die de accountant vervult niet uitsluitend om de ,slotverantwoording" gaat doch ten behoeve van de inwendige organisatie ook om de verantwoordingen op de verschillende niveau's van leiding ${ }^{8}$ ).

Indien ik Pon zou volgen in zijn gedachtengang dat de administratie zelfcontrolerend moet zijn en indien ik dat dan zou enten op de nieuwe definitie van ,administreren" dan vraag ik mij af of Pon ,het controleren van de administratie" in de zin van de vaststelling dat ze zelfcontrolerend is, niet zou moeten herintroduceren. Eenzelfde gedachtengang dus als met betrekking tot de steekproef: het nieuwe dat vroeger in de plaats kwam van het oude wordt nu het oude en het oude van vroeger wordt nu het nieuwe. Ik pleit daar zeker niet voor want het zou een zelfde naam zijn voor een handeling die een geheel andere functie in het geheel heeft. Waarmede slechts gezegd wil zijn, dat mijns inziens Pon niet zo denigrerend had mogen spreken over ,de administratie controleren".

(3) Op de bladzijden 15, 16 en 17 geeft Pon een korte beschrijving van de controlewerkzaamheden die gericht zijn op zijn eerste object van controle namelijk het onderzoek of een gegeven administratieve organisatie voldoet aan de eis dat zij tot op directieniveau een ,juiste" verantwoording moet opleveren en de vaststelling dat in haar werking niet is ingegrepen. Hier voelen wij ons weer tezamen: zoals reeds eerder is aangetoond zijn zowel het doel als de verrichtingen in dit opzicht gelijk in de huidige en in Pon's conceptie. Gegeven deze omstandigheden maak ik er echter bezwaar tegen dat daar waar Pon het heeft over de noodzaak dat de accountant een eigen greep heeft op de mutaties in de activa en de passiva en op de specificatie van de resultaten, hij gespatieerd vermeldt: ,zij het met een naar de omstandigheden en door de doelstelling van zijn onderzoek bepaalde tolerantie." Ik heb er geen bezwaar tegen dat schrijver niet aanduidt hoe de accountant die eigen greep verkrijgt. Dat zal bij de nieuwe en huidige conceptie wel niet veel verschillen. Maar als men in een betoog gespatieerde druk gebruikt, bedoelt men op dat deel van zijn betoog de nadruk te leggen. Dat misverstand had Pon niet mogen creëren. Hij kan toch immers niet hebben bedoeld dat deze overweging inhaerent is aan de nieuwe conceptie? In zijn - uiteraard korte - beschouwing over de steekproef is deze

${ }^{8}$ ) Zie ook ten deze het eerder genoemde artikel van Prof. v. Rietschoten in het Tijdschrift van de Maatschappij voor Nijverheid en Handel. 
gespatieerde zin eveneens de conclusie. Ook in dat opzicht is dit toch evenmin iets nieuws!

Moet uit hetgeen Pon op bladzijde 18 beweert, namelijk dat bij zijn voorgestane controlesysteem de dynamisering van de controle ook ten aanzien van andere activa dan voorraden kan worden toegepast, worden geconcludeerd dat zij die zulks bij de huidige controle-conceptie reeds sinds lange tijd doen, zoals schrijver dat zegt: ,in de controle-arbeid functioneel tekort schieten"? Groeneveld heeft in zijn eerder genoemde inleiding de vaktechnische overwegingen beschreven die een rol spelen bij de vraag of al dan niet kan worden gedynamiseerd zodat ik kan volstaan met een verwijzing naar diens inleiding. Ik moge enkel nog opmerken dat het in het vakjargon bekende begrip "balanscontrole" ook op het punt staat in de huidige conceptie uit de tijd te zijn. Alle controlehandelingen gericht op het uiteindelijke doel vormen immers één organisch geheel. Wat betreft het tijdstip waarop de handelingen zullen worden verricht gaat het er alleen om vast te stellen welke handelingen het doelmatigst gedurende het verslagjaar dan wel per het einde daarvan kunnen plaats vinden.

Ook blijkt uit de inleiding van Groeneveld inzake de dynamisering van de accountantscontrole dat het bij de ,spreiding van de balanscontrole" niet alleen gaat om de constatering van het bestaan van activa en passiva doch ook om hun waardering (bijvoorbeeld van voorraden en debiteuren).

(4) Op bladzijde 11 geeft Pon in overweging de leer van de administratieve organisatie en de leer van de accountantscontrole tezamen verantwoordingswetenschappen te noemen, zoals hij zegt in het voetspoor en met de motivering van de paritaire commissie van N.I.v.A. en V.A.G.A. Noch op grond van het feit dat ooit van rekeningswetenschappen is gesproken en dat de paritaire commissie in de reglementen over "verantwoording" in plaats van over "rekening en verantwoording" wenst te spreken, omdat daaruit niets ten aanzien van de benaming van de leren mag worden afgeleid, noch op grond van de inhoud van beide leren zou ik de benaming ,verantwoordingswetenschappen" een juiste aanduiding vinden. Ik houd het voorlopig op de zelfstandige benamingen.

Ik heb dit artikel bedoeld als een positieve bijdrage tot de beroepsontwikkeling. Het artikel van Pon heeft mij daartoe de annleiding gegeven. Ik hoop erin te zijn geslaagd de gedegenheid van de ons door onze voorgangers gegeven grondslagen aan te tonen. Door de daarin structueel verankerde evolutie-vatbaarheid en rationalisatie-eis blijven deze grondslagen hun geldigheid onverminderd behouden. In het boek van Peter Drucker "The landmarks of to-morrow" heb ik gelezen dat vernieuwing geen statisch maar een dynamisch begrip is, inhaerent aan ieder bestaan, en dus ook aan de leer van de accountantscontrole. De beroepsgenoten die de verschillende fasen in de ontwikkeling hebben meegemaakt, hebben steeds kunnen constateren dat de grondslagen onder de zich steeds wijzigende omstandigheden hun geldigheid bleven behouden. Ik heb in dit artikel getracht aan te tonen dat van een evolutie, in de zin van "dynamische" vernieuwing, sprake is evenals ik in het Limpergnummer een poging heb gedaan het bewijs te leveren dat het afwijzende standpunt van Limperg ten aanzien van de steekproef in de accountantscontrole niet de af- 
wijzing behoeft te betekenen van de plaats die de steekproef nu aan het innemen is.

Als Pon zegt dat de accountant de praktische inhoud van zijn verklaring meer naar buiten moet brengen dan ben ik dat volledig met hem eens.

Dat de tijd rijp is voor de concretisering van de ontwikkeling in de vorm van een heroriëntering met betrekking tot de leerstof voor het vak controleleer van het N.I.v.A. en dat dit vak dan de "leer van de accountantscontrole" zou moeten heten, dat staat naar ik aanneem voor Pon evenzeer vast als voor mij. 